The FASEB Journal express article 10.1096/fj.05-4564fje. Published online December 21, 2005.

\title{
Essential role for the Menkes ATPase in activation of extracellular superoxide dismutase: implication for vascular oxidative stress
}

\author{
Zhenyu Qin, Shinichi Itoh, Viktoria Jeney, Masuko Ushio-Fukai, and Tohru Fukai
}

Division of Cardiology, Department of Medicine, Emory University School of Medicine, Atlanta, GA

Corresponding author: Tohru Fukai, Division of Cardiology, Emory University School of Medicine, 101 Woodruff Circle, WMB 319, Atlanta, GA 30322. E-mail: tfukai@emory.edu

\begin{abstract}
\end{abstract}
Extracellular superoxide dismutase (SOD3), a secretory copper enzyme, plays an important role in atherosclerosis and hypertension by modulating the levels of extracellular superoxide anion $\left(\mathrm{O}_{2}{ }^{--}\right)$in the vasculature. Little is known about the mechanisms by which SOD3 obtains its catalytic copper cofactor. Menkes ATPase (MNK) has been shown to transport cytosolic copper to the secretory pathway in nonvascular cells. We performed the present study to determine whether MNK is required for the activation of SOD3 in the vasculature. Here we show that MNK was highly expressed in the various vascular tissues and cells. Aortas and cultured fibroblasts from MNK mutant (MNK ${ }^{\mathrm{mut}}$ ) mice showed a marked decrease in specific activity of SOD3, but not SOD1 (cytosolic form), which was partially restored by copper addition. Copper treatment in wild-type cells promoted the direct interaction and colocalization of SOD3 with MNK in the trans-Golgi network (TGN), suggesting that MNK transports copper to SOD3 in the TGN. Aortas of $\mathrm{MNK}^{\text {mut }}$ mice revealed a decrease in activity of SOD3, but not SOD1, in association with a robust increase in $\mathrm{O}_{2}{ }^{--}$levels. Finally, both MNK and SOD3 proteins were highly expressed in the intimal lesions of atherosclerotic vessels. In conclusion, vascular MNK plays an essential role in full activity of SOD3 through transporting copper to SOD3 in the TGN, thereby regulating $\mathrm{O}_{2}{ }^{--}$levels in the vasculature. These studies provide a novel insight into vascular MNK as a critical modulator of "superoxide" stress, which may contribute to cardiovascular disease.

Key words: SOD1 • SOD3 • atherosclerosis $\bullet$ copper $\bullet$ MNK

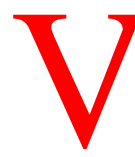

ascular superoxide anion $\left(\mathrm{O}_{2}{ }^{--}\right)$production contributes to the pathogenesis of many cardiovascular diseases, including atherosclerosis, hypertension, and diabetes $(1,2)$. The major cellular defense against $\mathrm{O}_{2}{ }^{--}$is a group of oxidoreductases known as superoxide dismutases (SODs). In mammalian tissue, three isoforms of SODs exist: the cytoplasmic $\mathrm{Cu} / \mathrm{Zn}$ SOD (SOD1), the mitochondrial Mn SOD (SOD2), and the extracellular SOD (SOD3). SOD3 is highly expressed in the vasculature, which is synthesized by vascular smooth muscle cells and fibroblasts, and is the major SOD in the extracellular space (3). It is secreted and 
anchored to the extracellular matrix and endothelial cell surface through binding to the heparan sulfate proteoglycan, collagen, and fibulin-5 (3-5). Because of its extracellular location, SOD3 plays an important role in regulating blood pressure and endothelial function by modulating the levels of extracellular $\mathrm{O}_{2}{ }^{--}$and nitric oxide bioactivity in the vasculature $(3,6,7)$. Recently, the R213G polymorphism in the SOD3 gene, which reduces binding to endothelial surface and increases serum SOD3 levels, has been linked to an increase in cardiovascular risk (8).

SOD3 is a secretory copper-containing enzyme with a similar active site to that of the SOD1. It has been shown that the SOD activity of both wild-type SOD1 and SOD3 depends critically on the presence of the copper ion at its native metal binding sites (9-11). Indeed, the mechanism of scavenging $\mathrm{O}_{2}{ }^{--}$by SOD involves alternate reduction and reoxidation of the copper ion at the active site of the enzyme. Under physiological conditions, the level of intracellular free copper is extraordinarily restricted (12). Thus, SOD1 obtains its catalytic copper ion through interaction with the cytosolic carrier protein CCS (copper chaperone for SOD1) $(13,14)$. In contrast, the cytosolic copper chaperone Atox1, not CCS, is required for full activation of SOD3 (11). Note that SOD3 secretes through endoplasmic reticulum-Golgi pathway where Atox1 does not exist. Thus, the cytosolic Atox1 itself is required, but not sufficient for delivering copper to SOD3 protein to regulate its full activity.

Menkes ATPase (ATP7A, MNK) plays a key role in copper transport from the cytosol into the secretory pathways $(15,16)$. A loss-of-function X-linked mutation of MNK leads to Menkes disease, a disorder characterized by the marked decrease in copper levels in most tissues except for the kidney and small intestine. Menkes patients show multiple abnormalities secondary to deficiencies in the activity of some secretory copper enzymes, such as dopamine $\beta$ monooxygenase (neurological abnormalities), tyrosinase (hypopigmentation), and lysyl oxidase (vascular abnormalities and connective tissue abnormalities), leading to death in infancy (16). Importantly, immunocytochemical studies in cultured cells demonstrated that under normal concentration of copper, MNK is localized to the trans-Golgi network, where MNK delivers copper to some secretory copper enzymes $(17,18)$. However, there is no information regarding whether MNK is required for delivering copper to SOD3.

In the current study, using two different MNK mutant mice with reduced copper transport function (19-25), we provide the first evidence that MNK is highly expressed in the vasculature and that MNK is required for full activation of vascular SOD3 by transporting copper to SOD3 in the trans-Golgi network, thereby regulating $\mathrm{O}_{2}{ }^{--}$levels in the vasculature. Of note, the copper transport to SOD3 by MNK is mediated through direct protein-protein interaction. Moreover, both MNK and SOD3 proteins are highly expressed in the intimal lesions of atherosclerotic vessels. These studies provide a novel insight into vascular MNK as a critical modulator of "superoxide" stress, which may contribute to cardiovascular disease.

\section{MATERIALS AND METHODS}

\section{Materials, animals, and cell culture}

All reagents were purchased from Sigma (St. Louis, MO), except when specified. The fibroblasts derived from male brindled MNK mutant mice, the corresponding wild-type cells (21-23), and antibody against the peptides 1445-1465 (SEPDKHSLLYGDFREDDDTTL) of murine MNK 
(26) are a kind gift from Dr. Jonathan Gitlin (Washington University School of Medicine, St. Louis, MO). The specificity of this murine Menkes ATPase antibody was confirmed by Western analysis and immunofluorescence showing a significant decrease in the immunofluorescence signal in MNK mutant cells despite normal integrity of the Golgi, as revealed by GS28 staining (26). The human MNK cDNA in pWSK29 was a kind gift from Dr. Julian Mercer (Deakin University, Australia) (27). The polyclonal antibody for SOD3 detection has been described previously (28). Other antibodies were obtained commercially, including anti- $\gamma$-adaptin (BD Biosciences, San Jose, CA), anti- $\mathrm{V}_{5}$ (Invitrogen, Carlsbad, CA), anti-SOD1 (BioDesign International, Kennebunk, ME), a biotin-conjugated goat anti-rabbit IgG, and anti-rabbit IgG (Bio-Rad Laboratories, Hercules, CA). C57BL/6J mice and ApoE ${ }^{-/-}$mice on a C57BL/6J background were obtained from the Jackson Laboratory (Bar Harbor, ME). The heterozygous blotchy MNK mutant mouse females and wild-type males were also obtained from Jackson Laboratory, used for establishing a colony, and maintained on regular chow. In the current study, male hemizygous mice carrying X-linked blotchy MNK mutation and control littermates were used. CHO cells stably expressing SOD3 were maintained as described previously (5). Experiments were performed with $1 \%$ serum with no additives. Transient transfection of human MNK cDNA in pWSK29 into CHO cells was performed using the PolyFect transfection reagent (Qiagen, Valencia, California) according to the manufacturer's recommendations.

\section{Western blot analysis}

Western blot analysis was performed as described previously (28). The primary antibodies used included a rabbit polyclonal antibody against murine SOD3 (28), a sheep antibody against human SOD1, and rabbit polyclonal antisera to MNK. Equal loading of proteins was confirmed by Ponceau or Coomassie blue staining.

\section{SOD activity assays}

SOD activity was assayed by monitoring inhibition of the rate of xanthine/xanthine oxidasemediated reduction of cytochrome $c$ as described previously (28). Con A-Sepharose chromatography (Amersham Biosciences, Piscataway, NJ) was used to isolate SOD3 from vessels of MNK mutant mice and their control littermates and the conditioned culture media of MNK mutant and wild-type cells as described previously $(11,28)$.

\section{$\mathrm{Cu}^{2+}$ affinity chromatography}

The $\mathrm{Cu}^{2+}$ affinity of SOD3 in the conditioned culture medium from MNK mutant and wild-type cells was assessed as previous described (29). Briefly, copper affinity column was prepared using a $1 \mathrm{ml}$ HiTrap chelating column (Amersham Biosciences), and copper was coupled to the columns by applying $0.1 \mathrm{M} \mathrm{CuCl}_{2}$. Excess metal was then removed from each column using equilibrated buffer (20 mM Tris $\mathrm{Cl}$ and $0.5 \mathrm{M} \mathrm{NaCl}, \mathrm{pH} 7.2$ ). The sample was then loaded onto each copper-bound column, followed by washing thoroughly with equilibrated buffer. The copper binding proteins were eluted with increasing concentration of imidazole (0-100 mM) in the equilibrated buffer. All fractions were concentrated using Amicon Ultra-30 centrifugal filter devices (Millipore, Billerica, MA), and analyzed by Western blot analysis as described above. 


\section{Confocal immunofluorescence analysis}

For this analysis (30), we used cultured mouse fibroblasts on coverslips fixed in $4 \%$ paraformaldehyde, permeabilized in $0.1 \%$ Triton X-100, and incubated with chicken anti-MNK antibody (1:100) followed by incubation with FITC-conjugated goat antibodies to chicken IgG (1:100) (Santa Cruz Biotechnology, Santa Cruz, CA), and rabbit anti-SOD3 antibody (1:100), followed by incubation with rhodamine-conjugated goat antibodies to rabbit IgG (1:100) (Santa Cruz Biotechnology). In other experiments, cells were stained with a mouse monoclonal antibody against $\gamma$-adaptin (1:500; Santa Cruz Biotechnology), followed by a biotin-conjugated rabbit anti-murine IgG (1:200; Bio-Rad Laboratories). Cells were examined with a Bio-Rad MRC 1024 confocal microscope, using argon laser excitation lines of 488 and $514 \mathrm{~nm}$ with emission filters of 540/30 and 580/32 nm.

\section{Subcellular fractionation analysis}

Subcellular fractionation was performed as described previously (30-32). Briefly, following two rinses with ice-cold PBS, confluent cells were lysed in $50 \mathrm{mM}$ Tris- $\mathrm{HCl}$, $\mathrm{pH}$ 7.5, $5 \mathrm{mM} \mathrm{MgCl}$, $25 \mathrm{mM} \mathrm{KCl}, 0.25 \mathrm{M}$ sucrose, and a protease inhibitor cocktail (Roche Applied Science, Indianapolis, IN). Following lysis, cells were disrupted by 20 strokes with a tight-fitting glass Dounce homogenizer, and the postnuclear supernatants were isolated by centrifugation at $500 \mathrm{~g}$ for 5 min. This supernatant was then subjected to discontinuous sucrose density gradient fractionation as described previously (31,32). A total of six fractions were collected from each gradient at the following sucrose interfaces: 0.9-1.1 M, 1.1-1.2 M, 1.2-1.3 M, 1.3-1.4 M, 1.41.5 M, and 1.5-1.7 M. Fifty microliters of each fraction were used for Western analysis.

\section{Coimmunoprecipitation of SOD3 and MNK in stably transfected CHO cells and in mouse fibroblasts}

Coimmunoprecipitation was performed as described previously (5).

\section{In vitro pull down assays using recombinant SOD3 with $\mathrm{V}_{5}$-His tag in mouse fibroblasts}

Human recombinant SOD3 with $\mathrm{V}_{5}$-His tag was produced in a Drosophila expression system (Invitrogen) as reported previously (11). Mouse fibroblast cells were lysed with $500 \mu \mathrm{l}$ of 50 $\mathrm{mmol} / \mathrm{l}$ Tris-HCl buffer containing $0.1 \mathrm{mmol} / \mathrm{l}$ EDTA, $0.1 \mathrm{mmol} / \mathrm{l}$ EGTA, $1 \%$ Triton X-100, and a protease inhibitor cocktail (Roche Applied Science). For in vitro pull down assays, one microgram of recombinant SOD3 protein was incubated with mouse fibroblast cell lysates (200 $\mu \mathrm{g})$ and $1 \mu \mathrm{g}$ of anti-His-tag antibody (Cell Signaling Technology, Beverley, MA) overnight at $4^{\circ} \mathrm{C}$ with constant rocking. The immunocomplexes were captured with $20 \mu \mathrm{l}$ of protein A/G agarose beads (Santa Cruz Biotechnology) and incubated at $4^{\circ} \mathrm{C}$ for $1.5 \mathrm{~h}$. Immunoprecipitates were separated using SDS-PAGE and transferred to nitrocellulose membranes, and immunoblotted with anti-MNK, anti-Na, K-ATPase, and anti-V5 antibody. 
Measurements of vascular superoxide production in aortas from MNK mutant mice and control littermates

Animals were killed by $\mathrm{CO}_{2}$ inhalation. The aortas were rapidly removed and placed into chilled modified Krebs/HEPES buffer (composition in mmol/l: $\mathrm{NaCl}$ 99.01, $\mathrm{KCl}$ 4.69, $\mathrm{CaCl}_{2}$ 2.50, $\mathrm{MgSO}_{4}$ 1.20, $\mathrm{KH}_{2} \mathrm{PO}_{4}$ 1.03, $\mathrm{NaHCO}_{3}$ 25.0, Na-HEPES 20.0, and glucose 5.6; $\mathrm{pH}$ 7.4), cleaned of excessive adventitial tissue, and cut into 4- to 5-mm ring segments with care taken not to injure the endothelium. Vascular $\mathrm{O}_{2}{ }^{--}$production was determined using lucigenin-enhanced chemiluminescence as described previously. (33) This method has been validated for $\mathrm{O}_{2}{ }^{--}$ measurements in vascular tissue when low concentrations of lucigenin ( $5 \mu \mathrm{mol} / \mathrm{l})$ are used (34).

As a second approach to measure ROS production in vessels in situ, frozen cross-sections of aortas were stained with dihydroethidium (Molecular Probes, Eugene, OR) using a previously validated method (5).

\section{Immunohistochemical analysis}

Tissues were embedded in OCT (Miles Laboratories, Elkhart, IN) and frozen using liquid nitrogen. Cryosections were stained with either a rabbit polyclonal antibody against murine SOD3 $(1: 10,000)(28)$ or a rabbit polyclonal antibody against human MNK (1:100) (22), followed by a biotin-conjugated goat anti-rabbit IgG (1:100; Bio-Rad Laboratories). Staining was developed using the ABC-AP Kit (Vector Laboratories, Burlingame, CA).

\section{Statistical analysis}

All data are expressed as mean \pm SE. Data were compared between groups of cells and animals by $t$ test when one comparison was performed or by ANOVA for multiple comparisons. When significance was indicated by ANOVA, the Tukey-Kramer post hoc test was used to specify between group differences. Values of $P<0.05$ were considered statistically significant.

\section{RESULTS}

\section{Specific activity of SOD3 is decreased in cultured MNK mutant mouse fibroblasts}

Although the tissue expression of MNK is known to be widespread, its expression in the vasculature is not available. As shown in Fig. 1, MNK was abundantly expressed in vascular smooth muscle cells, vascular endothelial cells, fibroblasts, and aorta as $\sim 178 \mathrm{kDa}$ protein that has been reported in other cells (30).

To determine whether MNK is required for the full activity of SOD3, we used cultured brindled MNK mutant $\left(\mathrm{MNK}^{\mathrm{br}}\right)$ mouse fibroblasts, which have a deletion of two conserved amino acids (Ala799 and Leu800) and an impairment of copper transport function (21-23). SOD3 from the conditioned media of control and MNK mutant cells was purified using concanavalin A sepharose chromatography as described previously (11). Activity of SOD3 in the culture medium was robustly decreased in MNK mutant fibroblasts as compared with control cells, while protein levels of SOD3 were increased (Fig. 2A, 2B). Thus, the specific activity of SOD3, as determined by the ratio of SOD3 activity to SOD3 protein, was markedly decreased in MNK mutant 
fibroblasts (84.8 $\pm 1.2 \%$ decrease, $P<0.01)($ Fig. $2 C)$. In contrast, the activity, protein, and specific activity of SOD1 were not changed in MNK mutant fibroblasts (Fig. 2).

The copper affinity of SOD3, as determined by copper affinity chromatography, was not changed in MNK mutant cells, suggesting that the decrease in SOD3-specific activity in MNK mutant cells is not due to a decrease in copper affinity of SOD3 (Fig. 3A). However, specific activity of SOD3 purified from MNK mutant cells was partially restored by addition of copper (Fig. $3 B$ ). Although specific activity of SOD3 purified from control cells was not affected by copper addition (Fig. 3B), it was decreased by the copper chelator BCS (bathocuproine disulfonate) (data not shown). These results suggest that most of the enzyme secreted from control cells is fully metallated. Thus, MNK is required for copper loading to SOD3 for its full activity.

\section{Colocalization of SOD3 and MNK in the trans-Golgi network}

Since we found that specific activity of SOD3 is dependent on MNK, we next examined where MNK delivers copper to SOD3 in the secretory pathway. Confocal immunofluorescence analysis showed that MNK and SOD3 partially colocalized with $\gamma$-adaptin, a trans-Golgi network resident protein, in the perinuclear region (Fig. 4A). Furthermore, subcellular fractionation analysis demonstrated that MNK and SOD3 partially cofractionated with $\gamma$-adaptin, but not GM130, a cisGolgi resident protein (Fig. 4B). These results suggest that SOD3 colocalizes with MNK in the trans-Golgi network of the secretory pathway.

\section{SOD3 directly interacts with MNK in a copper-dependent manner}

To determine how SOD3 obtains copper through MNK, we performed coimmunoprecipitation of SOD3 and MNK in mouse fibroblasts. As shown in Fig. 5A, SOD3 was coimmunoprecipitated with MNK, which was enhanced by addition of copper in a dose-dependent manner. In contrast, their association was inhibited by the copper chelator BCS. The interaction of SOD3 and MNK was further confirmed using $\mathrm{CHO}$ cells cotransfected with both proteins (Fig. $5 B$ ). In vitro pull down assays demonstrated that interaction of SOD3 with MNK is direct and specific, because recombinant SOD3 bound to MNK protein, but not to unrelated protein Na, K, ATPase (Fig. $\underline{5 C}$. These data suggest that MNK directly interacts with SOD3 in a copper-dependent manner.

\section{MNK is required for full activation of SOD3 in vascular tissue}

To confirm further that MNK is required for the full activity of SOD3 in vivo, we employed aortas from MNK mutant mice and control littermates. Since male brindled MNK mutant mice die at around $15 \mathrm{~d}$ after birth (19), we used male mice carrying the X-linked blotchy MNK mutation $\left(\mathrm{MNK}^{\text {blo }}\right)$ which have splice site mutations with stop codon at amino acid residue 794 with impaired copper transport function, but survive more than six months of age $(19,20,25)$. Consistent with the results obtained with cultured fibroblasts from the brindled MNK mutant mice, activity of SOD3 was markedly decreased in aortas from the $\mathrm{MNK}^{\text {blo }}$ mutant mice compared with those from control littermates, while protein levels of SOD3 were significantly increased (Fig. 6A, 6B). In contrast, the activity and protein of SOD1 were not altered in aortas from MNK ${ }^{\text {blo }}$ mutant mice (Fig. $\left.6 A, \underline{6 B}\right)$. Thus, the specific activity of SOD3, but not SOD1, was robustly decreased in aortas from $\mathrm{MNK}^{\text {blo }}$ mutant mice $(90 \pm 3.4 \%$ decrease, $P<0.01)$ (Fig. $6 C$ ). 
Taken together, these findings indicate that loss of MNK function markedly decreased the specific activity of SOD3, but not SOD1, in vascular tissue.

\section{Increased vascular $\mathrm{O}_{2}{ }^{--}$production in MNK mutant mice}

To determine the functional significance of MNK in modulating SOD3 activity in vivo, we measured $\mathrm{O}_{2}{ }^{--}$production in aortas from control and $\mathrm{MNK}^{\text {blo }}$ mutant mice using lucigeninenhanced chemiluminescence. We found that vascular $\mathrm{O}_{2}{ }^{--}$was markedly increased in aortas from MNK mutant mice as compared with those from control littermates (Fig. 7A). To estimate

$\mathrm{O}_{2}{ }^{-}$- production in mouse aortas in situ, we also used the dihydroethidium (DHE) fluorescence method. DHE is a fluorescent dye that has been shown to specifically detect $\mathrm{O}_{2}{ }^{--}$in situ $(5,35)$. DHE staining clearly demonstrated that $\mathrm{O}_{2}{ }^{--}$production was markedly increased in all layers of aortas from MNK mutant mice (Fig. 7B). Importantly, the fluorescence signal was markedly decreased by the addition of SOD, suggesting that the DHE signal mainly reflects an increase in $\mathrm{O}_{2}{ }^{\bullet-}$. Taken together, these findings suggest that MNK plays an important role in regulating vascular $\mathrm{O}_{2}{ }^{--}$levels, at least in part, by modulating vascular SOD3 activity.

\section{MNK is highly expressed in the intimal lesions of atherosclerotic vessels}

To gain further insight into the role of MNK in modulating SOD3 activity in atherosclerosis in which SOD3 expression and $\mathrm{O}_{2}{ }^{--}$production are markedly increased (28), we performed immunohistochemical analysis of MNK protein in aortas from control and ApoE ${ }^{-/-}$mice. Aortas from control mice showed a staining of MNK and SOD3 in the medial layer, while aortas from $\mathrm{ApoE}^{-/-}$mice demonstrated an intense staining of $\mathrm{MNK}$ protein in the intimal lesion of atherosclerosis with a concomitant increase in SOD3 in the extracellular matrix (Fig. 8). Note that MNK was highly expressed in the endothelium in atherosclerotic vessels from $\mathrm{ApoE}^{-/-}$ mice.

\section{DISCUSSION}

MNK belongs to a large family of cation-transporting P-type ATPase, and plays a key role in transporting copper from the cytosol into the secretory pathways. Although MNK has been shown to be essential for full activity of some secretory copper enzymes such as tyrosinase and peptidylglycine $\alpha$-amidating monooxygenase in mammalian cells $(17,18)$, little is known about its role in the vasculature. Here we provide the first evidence that MNK is highly expressed in the vascular tissues and cells, and that MNK is required for full activation of the secretory copper enzyme SOD3 using cultured fibroblasts and aortas from MNK mutant mice (19, 20, 22, 23). Of note, activation of the cytosolic copper enzyme SOD1 is MNK-independent. Copper affinity chromatography analysis showed that the decrease in SOD3-specific activity in MNK mutant cells is not due to the reduced copper affinity of SOD3. Specific activity of SOD3 purified from MNK mutant cells is partially restored by copper addition. These findings indicate that MNK plays a critical role in delivering copper to SOD3 for its full activation. However, SOD3 activity is not completely inhibited in MNK mutant cells, suggesting that MNK-independent copper delivery pathway for SOD3 may also exist. It is not clear why copper addition could not completely restore specific activity of SOD3 purified from MNK mutant cells. This might be due to the possibility that added copper is not incorporated properly into the active site of SOD3 in 
MNK mutant cells. Consistent with our results, specific activity of other secretory copper enzyme such as peptidylglycine- $\alpha$-hydroxylating monooxygenase (PHM) in MNK mutant cells is less than that in wild-type cells after addition of copper (23).

SOD3 is a secretory copper enzyme containing a classical signal peptide that will direct SOD3 from the endoplasmic reticulum through the trans-Golgi network to the plasma membrane, thereby being secreted into the extracellular space (37). Since we found that specific activity of SOD3 is dependent on MNK, we next investigated the mechanisms by which MNK delivers copper to SOD3 in the secretory pathway. Both immunofluorescence and subcellular fraction analysis revealed that SOD3 partially colocalizes with MNK and $\gamma$-adaptin, a marker of the transGolgi network, suggesting that MNK transports copper to SOD3 in the trans-Golgi network. Moreover, coimmunoprecipitation and in vitro pull down assays demonstrated that MNK directly interacts with SOD3 in vivo and in vitro. Thus, these data suggest that MNK delivers copper to SOD3 in the trans-Golgi network through direct binding to SOD3. We also found that interaction of MNK with SOD3 is copper-dependent. To our knowledge, this is the first evidence that MNK directly interacts with its target secretory copper enzyme in a copper-dependent manner. The detailed mechanisms of how SOD3 obtains copper from MNK require further investigation.

Since the level of intracellular free copper is extraordinarily restricted (12), MNK requires cytosolic copper carrier proteins to deliver copper to SOD3 in the trans-Golgi network (38). We have recently demonstrated that the copper chaperone Atox1 is involved in copper delivery to SOD3 (11). There are several proteins such as MNK, WND (ATP7B), and FKBP52 (39) that receive copper from Atox1; however, it has been shown that Atox1 delivers copper to other secretory copper-containing enzymes via MNK in the yeast system $(40,41)$. Thus, it is likely that SOD3 may obtain copper through Atox1-MNK pathway in the vascular cells.

To determine the functional significance of MNK in modulating SOD3 activity in vivo, we measured $\mathrm{O}_{2}{ }^{\bullet-}$ levels in aortas from control and MNK mutant mice. Lucigenin chemiluminescence and SOD inhibitable DHE fluorescence assays demonstrated that vascular $\mathrm{O}_{2}{ }^{\bullet-}$ level was significantly increased in MNK mutant mice in which vascular SOD3 activity was markedly decreased. Neither hydroxyl radical, $\mathrm{NO}^{\bullet}$, peroxynitrite, $\mathrm{H}_{2} \mathrm{O}_{2}$, hypochlorite, or singlet $\mathrm{O}_{2}$ significantly oxidizes $\mathrm{HE}$ (43). In addition, since SOD cannot enter the intracellular space, the detected SOD inhibitable DHE signal may mainly reflect the $\mathrm{O}_{2}{ }^{--}$derived from extracellular space. Indeed, oxyethidium, a specific fluorescent product by the reaction of DHE and superoxide anion (42), is cell-permeable (unpublished observation). These results suggest that MNK plays an essential role in modulating $\mathrm{O}_{2}{ }^{--}$through regulating SOD3 activity in the vasculature.

$\mathrm{NO}^{\bullet}$ exerts myriads of biological effects, including dilation of vessels, inhibition of proliferation of vascular smooth muscle cells, and platelet aggregation (44). These properties are antiatherogenic and antihypertensive. Bioavailability of $\mathrm{NO}^{\bullet}$ can be regulated by extracellular $\mathrm{O}_{2}{ }^{\bullet-}$, because $\mathrm{NO}^{\bullet}$ and $\mathrm{O}_{2}{ }^{\bullet-}$ undergo an extremely rapid, diffusion limited radical/radical reaction, leading to the formation of the potent oxidant peroxynitrite anion (44) that is involved in numerous pathophysiological processes (45). Endothelium-derived $\mathrm{NO}^{\bullet}$ must transverse the extracellular space between the endothelium and the smooth muscle to induce smooth muscle relaxation. Therefore, the increase in extracellular $\mathrm{O}_{2}{ }^{--}$production, at least in part, due to 
decrease in SOD3 activity in MNK mutant mice, may decrease the level of $\mathrm{NO}^{\bullet}$ in the vessel wall. Thus, MNK may play an important role in regulating available $\mathrm{NO}^{\bullet}$ to modulate vascular function.

To gain insight into the role of MNK in modulating SOD3 activity in atherosclerosis in which SOD3 expression and $\mathrm{O}_{2}{ }^{--}$production are markedly increased, we performed immunohistochemical analysis of MNK protein in atherosclerotic aorta from $\mathrm{ApoE}^{-/-}$mice. We found that MNK protein expression was highly expressed in the intimal lesion of atherosclerosis where SOD3 was markedly expressed in the extracellular matrix (Fig. 8). Of note, despite the specific activity of SOD3 is decreased in MNK mutant mice, the protein expression is rather increased in these mice (Fig. 1 and $\underline{5}$ ). We have previously shown that Atox1 functions not only as a copper chaperone but also as a positive regulator for SOD3 transcription (11). Atox1 is also markedly increased in the intimal lesion of atherosclerosis (11), and knockdown of Atox1 by siRNA completely abolishes the increase in SOD3 protein levels in MNK mutant cells (unpublished observation). Thus, these findings suggest that the increase in SOD3 protein levels in MNK mutant cells may be due to the up-regulation of Atox1. Note that some Menkes mutant mice, where SOD3 activity is markedly decreased, show vascular abnormalities including formation of aortic aneurysm (46), which is associated with oxidative stress $(47,48)$. Thus, it is conceivable that MNK also may be involved in aortic aneurysm formation by modulating vascular redox state via regulating SOD3 activity. Studies focused on the functional role of MNK and the mechanisms of how MNK regulates SOD3 expression in atherosclerosis and other cardiovascular diseases are subjects of further investigation.

In summary, the present study demonstrates that MNK plays an essential role in regulating SOD3 activity through transporting copper to SOD3 in the trans-Golgi network, thereby modulating vascular $\mathrm{O}_{2}{ }^{--}$levels. In the cardiovascular system, SOD3 is highly expressed in blood vessels and plays a major role in increasing nitric oxide bioactivity by scavenging extracellular $\mathrm{O}_{2}{ }^{-}$. Thus, our study should provide a novel insight into how redox state of blood vessel is tightly controlled by copper transport systems.

\section{ACKNOWLEDGMENTS}

We thank Dr. Jonathan Gitlin of Washington University in St. Louis for his gift of the brindled MNK mutant and wild-type mouse fibroblast cell lines and anti-MNK antibody, and for his helpful discussion. We also thank Dr. David G. Harrison for his helpful discussion, and Drs. Lian Zuo and Lula Hilenski for their technical assistance. This research was supported by NIH R01 HL70187, Program Project Grant HL58000, AHA National Scientist Development Grant 0030180N, and AHA Grant In Aid 0455242B.

\section{REFERENCES}

1. Griendling, K. K., and FitzGerald, G. A. (2003) Oxidative stress and cardiovascular injury: part I: basic mechanisms and in vivo monitoring of ROS. Circulation 108, 1912-1916

2. Griendling, K. K., and FitzGerald, G. A. (2003) Oxidative stress and cardiovascular injury: part II: animal and human studies. Circulation 108, 2034-2040 
3. Fukai, T., Folz, R. J., Landmesser, U., and Harrison, D. G. (2002) Extracellular superoxide dismutase and cardiovascular disease. Cardiovasc. Res. 55, 239-249

4. Petersen, S. V., Oury, T. D., Ostergaard, L., Valnickova, Z., Wegrzyn, J., Thogersen, I. B., Jacobsen, C., Bowler, R. P., Fattman, C. L., Crapo, J. D., et al. (2004) Extracellular superoxide dismutase (EC-SOD) binds to type I collagen and protects against oxidative fragmentation. J. Biol. Chem. 279, 13705-13710

5. Nguyen, A. D., Itoh, S., Jeney, V., Yanagisawa, H., Fujimoto, M., Ushio-Fukai, M., and Fukai, T. (2004) Fibulin-5 is a novel binding protein for extracellular superoxide dismutase. Circ. Res. 95, 1067-1074

6. Jung, O., Marklund, S. L., Geiger, H., Pedrazzini, T., Busse, R., and Brandes, R. P. (2003) Extracellular superoxide dismutase is a major determinant of nitric oxide bioavailability: in vivo and ex vivo evidence from ecSOD-deficient mice. Circ. Res. 93, 622-629

7. Chu, Y., Iida, S., Lund, D. D., Weiss, R. M., DiBona, G. F., Watanabe, Y., Faraci, F. M., and Heistad, D. D. (2003) Gene transfer of extracellular superoxide dismutase reduces arterial pressure in spontaneously hypertensive rats: role of heparin-binding domain. Circ. Res. 92, 461-468

8. Juul, K., Tybjaerg-Hansen, A., Marklund, S., Heegaard, N. H., Steffensen, R., Sillesen, H., Jensen, G., and Nordestgaard, B. G. (2004) Genetically reduced antioxidative protection and increased ischemic heart disease risk: the Copenhagen City Heart Study. Circulation 109, $59-65$

9. McCord, J. M., and Fridovich, I. (1969) Superoxide dismutase. An enzymic function for erythrocuprein (hemocuprein). J. Biol. Chem. 244, 6049-6055

10. Valentine, J. S., Pantoliano, M. W., McDonnell, P. J., Burger, A. R., and Lippard, S. J. (1979) $\mathrm{pH}$-dependent migration of copper(II) to the vacant zinc-binding site of zinc-free bovine erythrocyte superoxide dismutase. Proc. Natl. Acad. Sci. USA 76, 4245-4249

11. Jeney, V., Itoh, S., Wendt, M., Gradek, Q., Ushio-Fukai, M., Harrison, D. G., and Fukai, T. (2005) Role of antioxidant-1 in extracellular superoxide dismutase function and expression. Circ. Res. 96, 723-729

12. Rae, T. D., Schmidt, P. J., Pufahl, R. A., Culotta, V. C., and O’Halloran, T. V. (1999) Undetectable intracellular free copper: the requirement of a copper chaperone for superoxide dismutase. Science 284, 805-808 (see comments)

13. O’Halloran, T. V., and Culotta, V. C. (2000) Metallochaperones, an intracellular shuttle service for metal ions. J. Biol. Chem. 275, 25057-25060

14. Bartnikas, T. B., and Gitlin, J. D. (2001) How to make a metalloprotein. Nat. Struct. Biol. 8, 733-734 
15. Schaefer, M., and Gitlin, J. D. (1999) Genetic disorders of membrane transport. IV. Wilson’s disease and Menkes disease. Am. J. Physiol. 276, G311-G314

16. Mercer, J. F. (2001) The molecular basis of copper-transport diseases. Trends Mol. Med. 7, 64-69

17. Petris, M. J., Strausak, D., and Mercer, J. F. (2000) The Menkes copper transporter is required for the activation of tyrosinase. Hum. Mol. Genet. 9, 2845-2851

18. Steveson, T. C., Ciccotosto, G. D., Ma, X. M., Mueller, G. P., Mains, R. E., and Eipper, B. A. (2003) Menkes protein contributes to the function of peptidylglycine alpha-amidating monooxygenase. Endocrinology 144, 188-200

19. Mercer, J. F. (1998) Menkes syndrome and animal models. Am. J. Clin. Nutr. 67, 1022S$1028 \mathrm{~S}$

20. La Fontaine, S., Firth, S. D., Lockhart, P. J., Brooks, H., Camakaris, J., and Mercer, J. F. (1999) Intracellular localization and loss of copper responsiveness of Mnk, the murine homologue of the Menkes protein, in cells from blotchy (Mo blo) and brindled (Mo br) mouse mutants. Hum. Mol. Genet. 8, 1069-1075

21. Kelly, E. J., and Palmiter, R. D. (1996) A murine model of Menkes disease reveals a physiological function of metallothionein. Nat. Genet. 13, 219-222

22. Payne, A. S., Kelly, E. J., and Gitlin, J. D. (1998) Functional expression of the Wilson disease protein reveals mislocalization and impaired copper-dependent trafficking of the common H1069Q mutation. Proc. Natl. Acad. Sci. USA 95, 10854-10859

23. El Meskini, R., Culotta, V. C., Mains, R. E., and Eipper, B. A. (2003) Supplying copper to the cuproenzyme peptidylglycine alpha-amidating monooxygenase. J. Biol. Chem. 278, 12278-12284

24. Royce, P. M., Camakaris, J., Mann, J. R., and Danks, D. M. (1982) Copper metabolism in mottled mouse mutants. The effect of copper therapy on lysyl oxidase activity in brindled (Mobr) mice. Biochem. J. 202, 369-371

25. Starcher, B., Madaras, J. A., Fisk, D., Perry, E. F., and Hill, C. H. (1978) Abnormal cellular copper metabolism in the blotchy mouse. J. Nutr. 108, 1229-1233

26. Hamza, I., Prohaska, J., and Gitlin, J. D. (2003) Essential role for Atox1 in the coppermediated intracellular trafficking of the Menkes ATPase. Proc. Natl. Acad. Sci. USA 100, $1215-1220$

27. La Fontaine, S., Firth, S. D., Lockhart, P. J., Brooks, H., Parton, R. G., Camakaris, J., and Mercer, J. F. (1998) Functional analysis and intracellular localization of the human menkes protein (MNK) stably expressed from a cDNA construct in Chinese hamster ovary cells (CHO-K1). Hum. Mol. Genet. 7, 1293-1300 
28. Fukai, T., Galis, Z. S., Meng, X. P., Parthasarathy, S., and Harrison, D. G. (1998) Vascular expression of extracellular superoxide dismutase in atherosclerosis. J. Clin. Invest. 101, 2101-2111

29. Landriscina, M., Bagala, C., Mandinova, A., Soldi, R., Micucci, I., Bellum, S., Prudovsky, I., and Maciag, T. (2001) Copper induces the assembly of a multiprotein aggregate implicated in the release of fibroblast growth factor 1 in response to stress. J. Biol. Chem. 276, 25549-25557

30. Yamaguchi, Y., Heiny, M. E., Suzuki, M., and Gitlin, J. D. (1996) Biochemical characterization and intracellular localization of the Menkes disease protein. Proc. Natl. Acad. Sci. USA 93, 14030-14035

31. Suga, K., Tomiyama, T., Mori, H., and Akagawa, K. (2004) Syntaxin 5 interacts with presenilin holoproteins, but not with their $\mathrm{N}$ - or C-terminal fragments, and affects betaamyloid peptide production. Biochem. J. 381, 619-628

32. Siman, R., and Velji, J. (2003) Localization of presenilin-nicastrin complexes and gammasecretase activity to the trans-Golgi network. J. Neurochem. 84, 1143-1153

33. Landmesser, U., Dikalov, S., Price, S. R., McCann, L., Fukai, T., Holland, S. M., Mitch, W. E., and Harrison, D. G. (2003) Oxidation of tetrahydrobiopterin leads to uncoupling of endothelial cell nitric oxide synthase in hypertension. J. Clin. Invest. 111, 1201-1209

34. Skatchkov, M. P., Sperling, D., Hink, U., Mulsch, A., Harrison, D. G., Sindermann, I., Meinertz, T., and Munzel, T. (1999) Validation of lucigenin as a chemiluminescent probe to monitor vascular superoxide as well as basal vascular nitric oxide production. Biochem. Biophys. Res. Commun. 254, 319-324

35. Miller, F. J., Jr., Gutterman, D. D., Rios, C. D., Heistad, D. D., and Davidson, B. L. (1998) Superoxide production in vascular smooth muscle contributes to oxidative stress and impaired relaxation in atherosclerosis. Circ. Res. 82, 1298-1305

36. Hellman, N. E., Kono, S., Mancini, G. M., Hoogeboom, A. J., De Jong, G. J., and Gitlin, J. D. (2002) Mechanisms of copper incorporation into human ceruloplasmin. J. Biol. Chem. 277, 46632-46638

37. Bowler, R. P., Nicks, M., Olsen, D. A., Thogersen, I. B., Valnickova, Z., Hojrup, P., Franzusoff, A., Enghild, J. J., and Crapo, J. D. (2002) Furin proteolytically processes the heparin-binding region of extracellular superoxide dismutase. J. Biol. Chem. 277, 1650516511

38. Pufahl, R. A., Singer, C. P., Peariso, K. L., Lin, S. J., Schmidt, P. J., Fahrni, C. J., Culotta, V. C., Penner-Hahn, J. E., and O'Halloran, T. V. (1997) Metal ion chaperone function of the soluble $\mathrm{Cu}(\mathrm{I})$ receptor Atx1. Science 278, 853-856 (see comments) 
39. Sanokawa-Akakura, R., Dai, H., Akakura, S., Weinstein, D., Fajardo, J. E., Lang, S. E., Wadsworth, S., Siekierka, J., and Birge, R. B. (2004) A novel role for the immunophilin FKBP52 in copper transport. J. Biol. Chem. 279, 27845-27848

40. Lin, S. J., Pufahl, R. A., Dancis, A., O’Halloran, T. V., and Culotta, V. C. (1997) A role for the Saccharomyces cerevisiae ATX1 gene in copper trafficking and iron transport. J. Biol. Chem. 272, 9215-9220

41. Hung, I. H., Casareno, R. L., Labesse, G., Mathews, F. S., and Gitlin, J. D. (1998) HAH1 is a copper-binding protein with distinct amino acid residues mediating copper homeostasis and antioxidant defense. J. Biol. Chem. 273, 1749-1754

42. Zhao, H., Kalivendi, S., Zhang, H., Joseph, J., Nithipatikom, K., Vasquez-Vivar, J., and Kalyanaraman, B. (2003) Superoxide reacts with hydroethidine but forms a fluorescent product that is distinctly different from ethidium: potential implications in intracellular fluorescence detection of superoxide. Free Radic. Biol. Med. 34, 1359-1368

43. Bindokas, V. P., Jordan, J., Lee, C. C., and Miller, R. J. (1996) Superoxide production in rat hippocampal neurons: selective imaging with hydroethidine. J. Neurosci. 16, 1324-1336

44. Darley-Usmar, V. M., McAndrew, J., Patel, R., Moellering, D., Lincoln, T. M., Jo, H., Cornwell, T., Digerness, S., and White, C. R. (1997) Nitric oxide, free radicals and cell signalling in cardiovascular disease. Biochem. Soc. Trans. 25, 925-929

45. O’Donnell, V. B., and Freeman, B. A. (2001) Interactions between nitric oxide and lipid oxidation pathways: implications for vascular disease. Circ. Res. 88, 12-21

46. Andrews, E. J., White, W. J., and Bullock, L. P. (1975) Spontaneous aortic aneurysms in blotchy mice. Am. J. Pathol. 78, 199-210

47. Miller, F. J., Jr., and Griendling, K. K. (2002) Functional evaluation of nonphagocytic NAD(P)H oxidases. Methods Enzymol. 353, 220-233

48. Gavrila, D., Li, W. G., McCormick, M. L., Thomas, M., Daugherty, A., Cassis, L. A., Miller, F. J., Jr., Oberley, L. W., Dellsperger, K. C., and Weintraub, N. L. (2005) Vitamin E inhibits abdominal aortic aneurysm formation in angiotensin II-infused apolipoprotein Edeficient mice. Arterioscler. Thromb. Vasc. Biol. 25, 1671-1677

Received July 4, 2005; accepted October 25, 2005. 
Fig. 1


Figure 1. Expression of MNK in the vasculature. Lysates from human fibroblasts, human aortic smooth muscle cells (HASM), human aortic endothelial cells (HAEC), human umbilical vein endothelial cells (HUVEC), and homogenates from mouse aorta were immunoblotted with anti-MNK antibody. Blots were representative of three experiments. 
Fig. 2

\section{A Activity in cultured mouse fibroblasts}
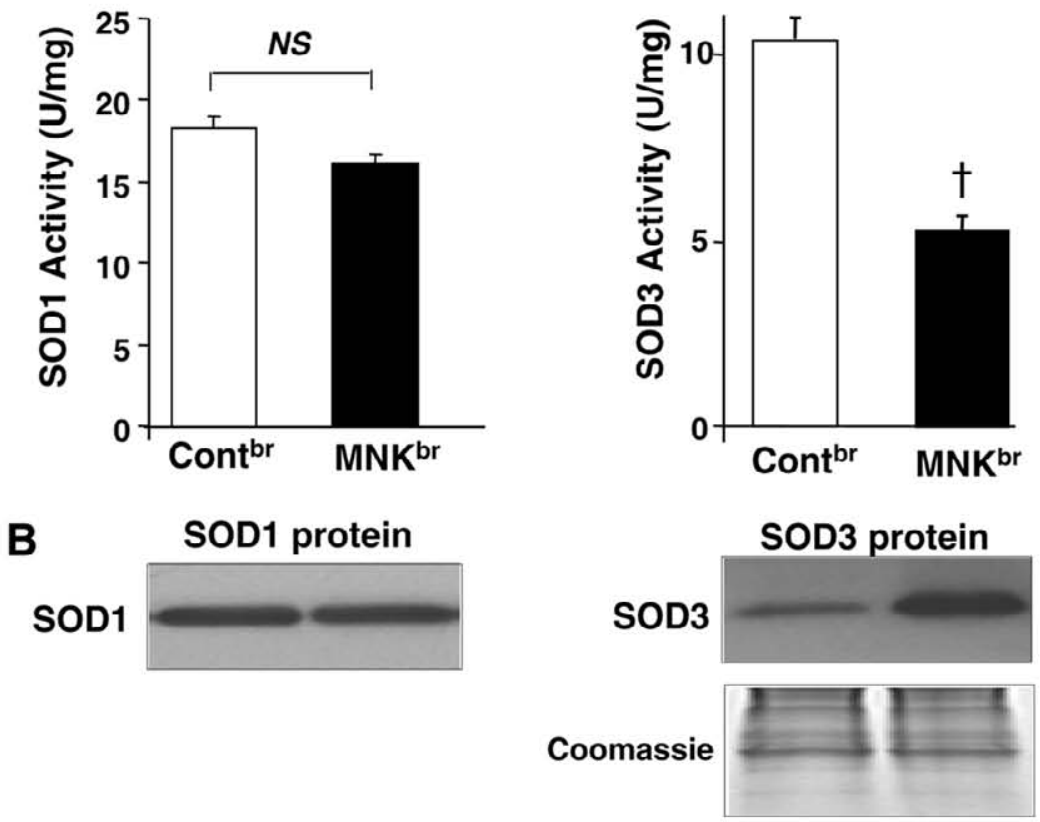

C Specific Activity in cultured mouse fibrobasts
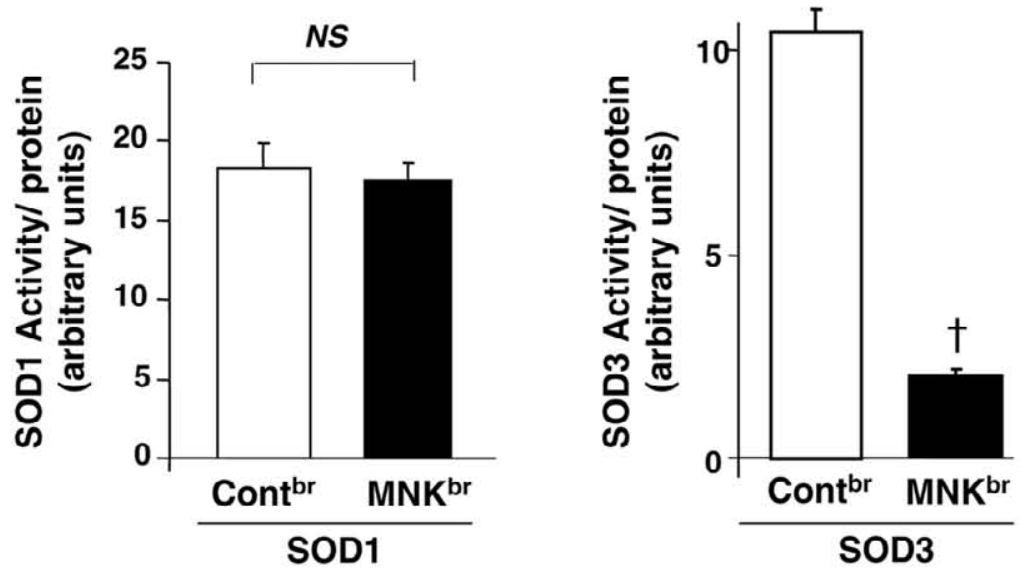

Figure 2. Activity $(\boldsymbol{A})$, protein expression $(\boldsymbol{B})$, and specific activity $(\boldsymbol{C})$ of secreted SOD3 and SOD1 in cultured control $\left(\right.$ Cont $\left.^{\mathrm{br}}\right)$ and brindled MNK mutant $\left(\mathrm{MNK}^{\mathrm{br}}\right)$ mouse fibroblasts (21-23). Cells were cultured in $1 \%$ serum containing DMEM for $72 \mathrm{~h}$. The SOD3 secreted in the culture medium was collected and concentrated by concanavalin-A sepharose chromatography. A) Activity of SOD3 in concentrated culture medium and SOD1 in cell lysates was assayed by examining the inhibition of cytochrome $c$ reduction by xanthine/xanthine oxidase at $\mathrm{pH} 7.4$ (28). The results are presented as mean \pm SE from 4 separate experiments. ${ }^{\dagger} P<0.01$ vs. control. NS, not significant. $\boldsymbol{B}$ ) Protein levels of SOD1 and SOD3 were determined by Western analysis with antibodies specific to either the SOD1 or the SOD3. Representative blots are from 4 individual experiments. $C$ ) Specific activity of SOD1 and SOD3 was determined by the ratio of activity to relative amount of protein as previously described (11). Equal protein loading was confirmed by Ponceau staining or Coomassie blue staining. The results are presented as mean \pm SE from 4 separate experiments. ${ }^{\dagger} P<0.01$ vs. control. NS, not significant. 
Fig. 3

A

SOD3 copper binding affinity
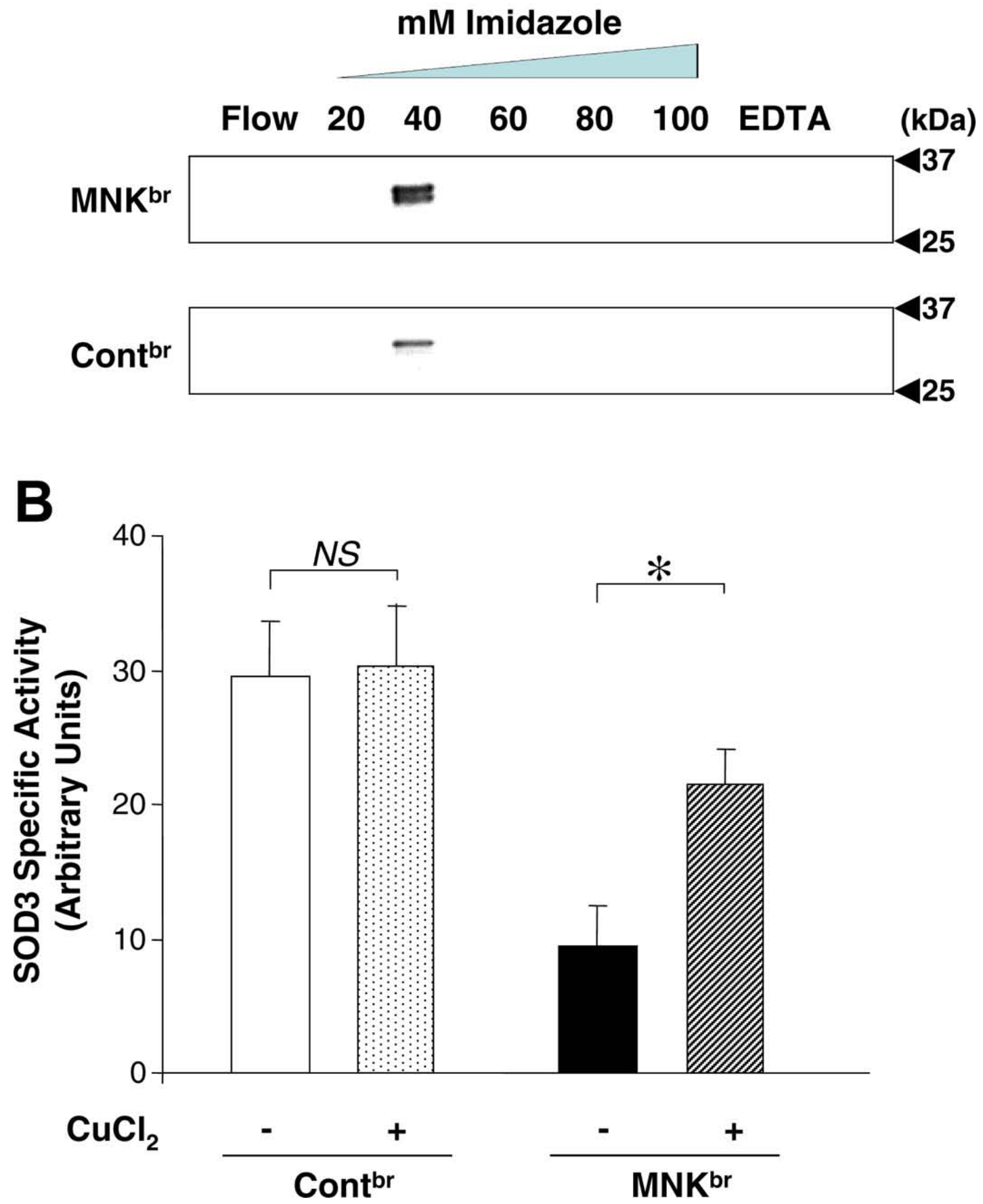

Figure 3. A) Copper binding affinity of SOD 3 secreted from control $\left(\mathrm{Cont}^{\mathrm{br}}\right)$ and brindled MNK mutant $\left(\mathrm{MNK}^{\mathrm{br}}\right)$ mouse $^{\mathrm{m}}$ fibroblasts (21-23). SOD3 protein in the conditioned medium was adsorbed to a $\mathrm{Cu}^{2+}$-affinity column and eluted with an imidazole gradient $(0-100 \mathrm{mM})$ as previously described (29). The column was stripped with $50 \mathrm{mM}$ EDTA, and all fractions, including the flow, were resolved by $15 \%$ acrylamide SDS/PAGE and assessed by SOD3 immunoblot analysis. $\boldsymbol{B})$ The effect of in vitro copper treatment on SOD3-specific activity purified from Cont ${ }^{\mathrm{br}}$ and $\mathrm{MNK}^{\mathrm{br}}$ mutant cells (21-23). Both cells were cultured in $1 \%$ serum containing DMEM for $72 \mathrm{~h}$, and the cultured medium was harvested and concentrated as described in Fig. 1. The relative SOD3 protein content was determined as described in Fig. 1. After equal amounts of SOD3 protein were treated with or without $\mathrm{CuCl}_{2}(10 \mu \mathrm{M}, 60 \mathrm{~min}$, at room temperature), SOD3 activity was measured. Graph shows mean data for 3 separate experiments. ${ }^{*} P<0.05$ vs. vehicle alone. NS, not significant. 
Fig. 4
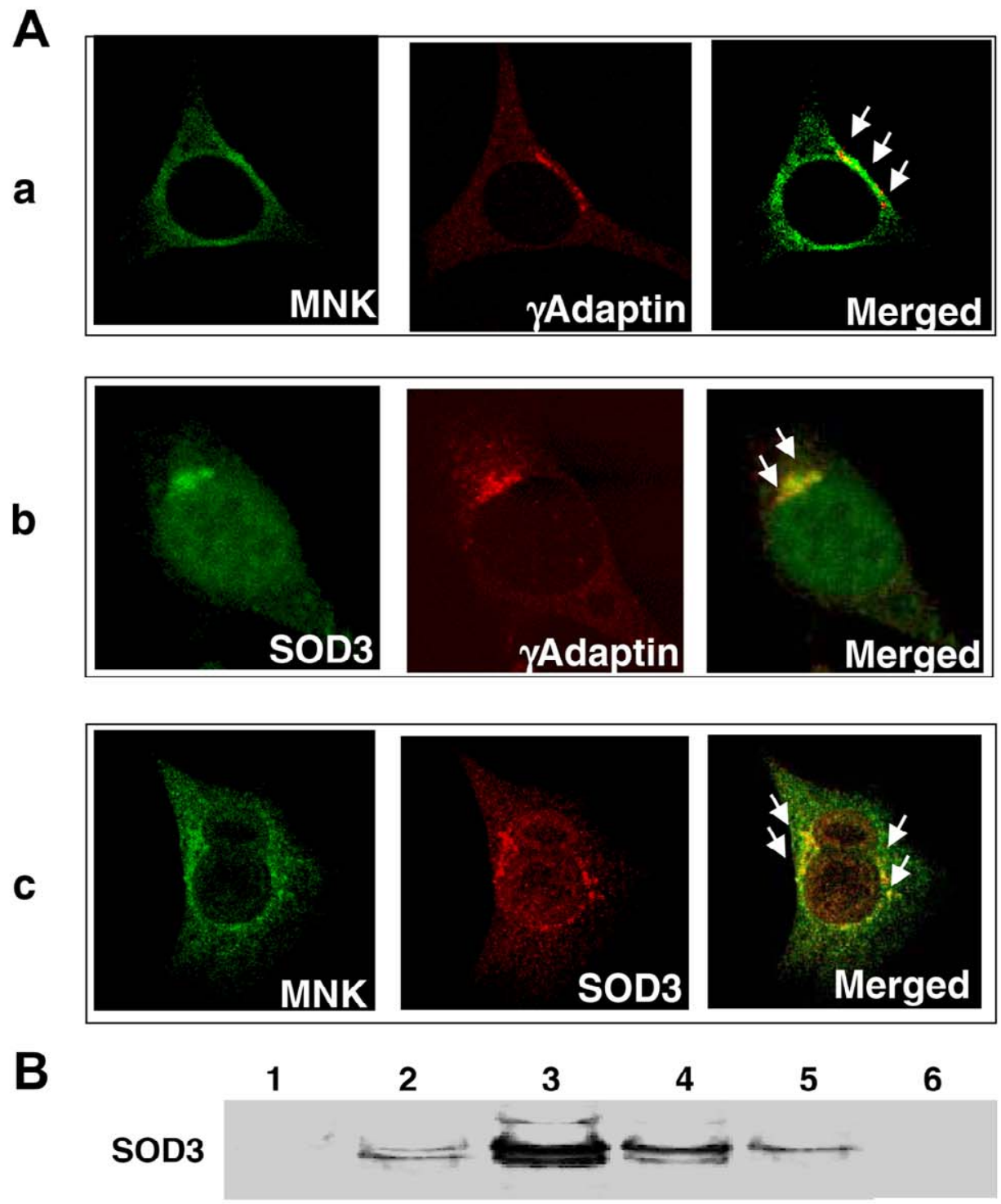

MNK

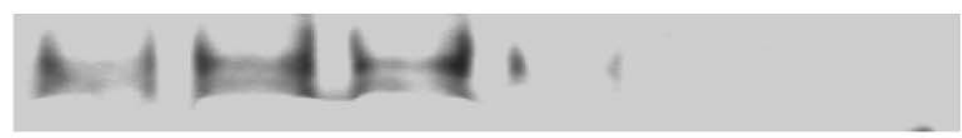

GM130

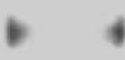

4

Adaptin Y

Figure 4. A) Localization of MNK and SOD3 in mouse fibroblasts by confocal immunofluorescence analysis with antibodies to MNK $(\boldsymbol{a}, \boldsymbol{c})$, SOD3 $(\boldsymbol{b}, \boldsymbol{c})$, and $\gamma$-adaptin $(\boldsymbol{a}, \boldsymbol{b})$. Right panels) Merged image from each double-labeling $(\times 400)$. The $\gamma$-adaptin was used as a marker for trans-Golgi network. $\boldsymbol{B})$ Localization of MNK and SOD3 by subcellular fractionation analysis of mouse fibroblasts. Immunoblotting of lysates was performed following discontinuous sucrose density gradient fractionation. Fifty microliters from each fraction was separated by SDS-PAGE and immunoblotted with antibodies to MNK, SOD3, $\gamma$-adaptin, and GM130. The $\gamma$-adaptin and GM130 were used as markers for trans-Golgi network and cis-Golgi, respectively. 
Fig. 5

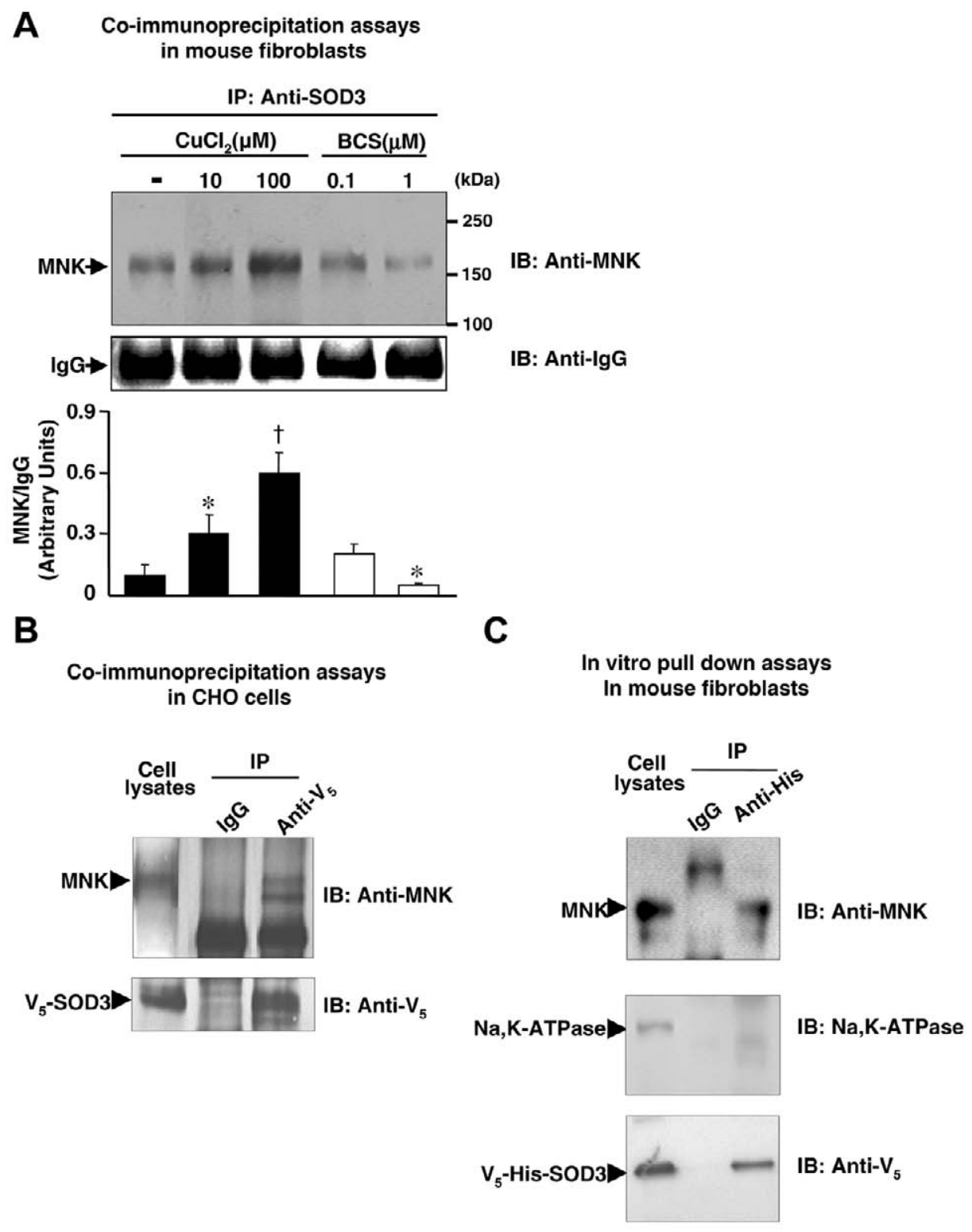

Figure 5. Coimmunoprecipitation of SOD3 and MNK in mouse fibroblasts $(\boldsymbol{A})$ and $\mathrm{CHO}$ cells stably transfected with $\mathrm{V}_{5^{-}}$ SOD3 $(\boldsymbol{B}) . \boldsymbol{A})$ Mouse fibroblasts were incubated with $\mathrm{CuCl}_{2}(0,10$, and $100 \mu \mathrm{M})$ or with the copper chelator BCS (bathocuproine disulfonate) $(0.1$ and $1 \mu \mathrm{M})$ for $12 \mathrm{~h}$. Equal amounts of lysates were immunoprecipitated (IP) with antimouse SOD3 antibody followed by immunoblotting (IB) with the anti-MNK antibody. IgG was included as a negative control for the immunoprecipitation and as an indicator of loading condition. The results are presented as mean \pm SE from 4 separate experiments. ${ }^{\dagger} P<0.01$ vs. nontreated cells. $* P<0.05$ vs. nontreated cells. $\left.\boldsymbol{B}\right)$ Two days after transient transfection with MNK cDNA, the cell lysates in CHO cells expressing $\mathrm{V}_{5}$-tagged SOD3 were immunoprecipitated (IP) with the antibody as indicated followed by immunoblotting (IB) with the anti-MNK antibody and the anti- $\mathrm{V}_{5}$ antibody to detect SOD3. IgG was included as a negative control for the immunoprecipitation. $\boldsymbol{C}$ ) In vitro pull-down assays using recombinant SOD3 with $\mathrm{V}_{5}$-His tag in mouse fibroblasts. Human recombinant SOD3 with $\mathrm{V}_{5}$-His tag was incubated with mouse fibroblast cell lysates, and the mixture was immunoprecipitated (IP) with anti-His antibody, followed by immunoblotting (IB) with anti-MNK, anti-Na, K-ATPase, and anti-V5 antibody. IgG was included as a negative control for the immunoprecipitation. Cell lysates were included as a positive control. 
Fig. 6

\section{A \\ Activity in mouse aorta}
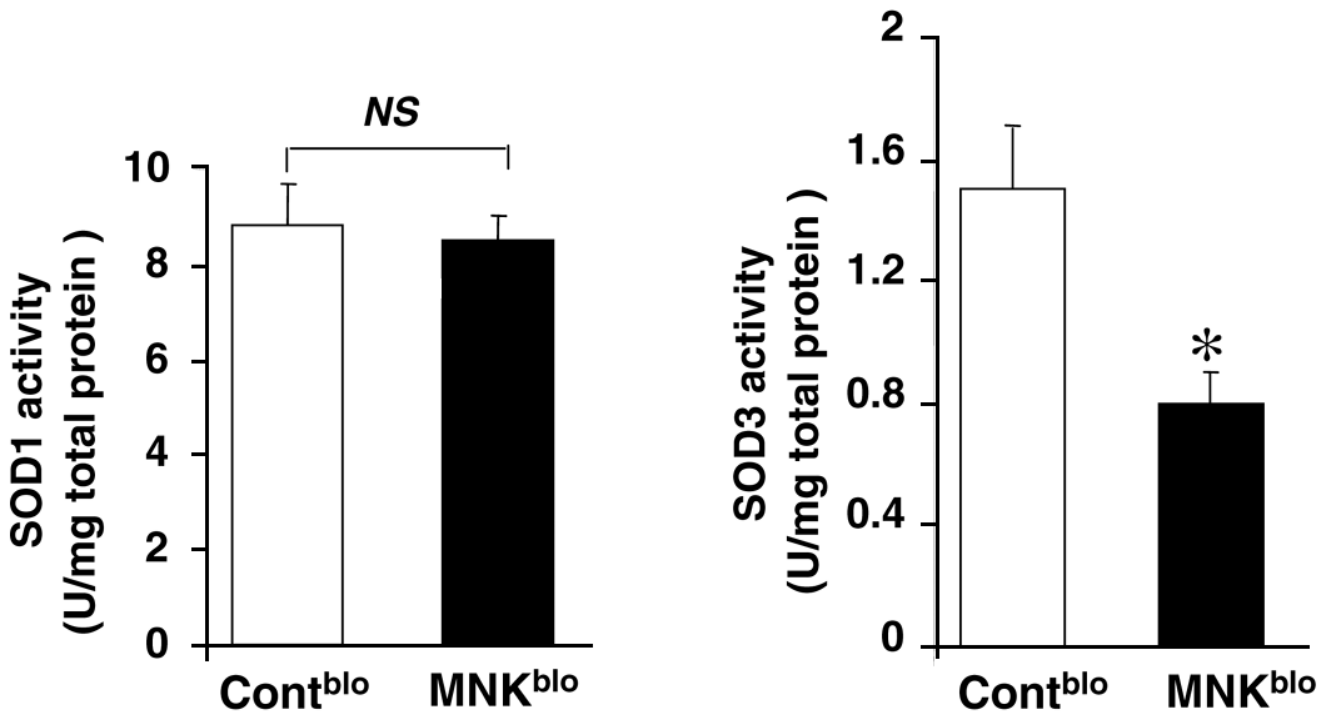

B

SOD1 Protein

SOD1

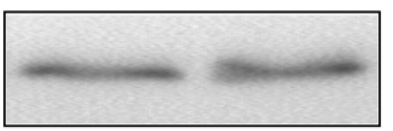

SOD3 Protein

SOD3
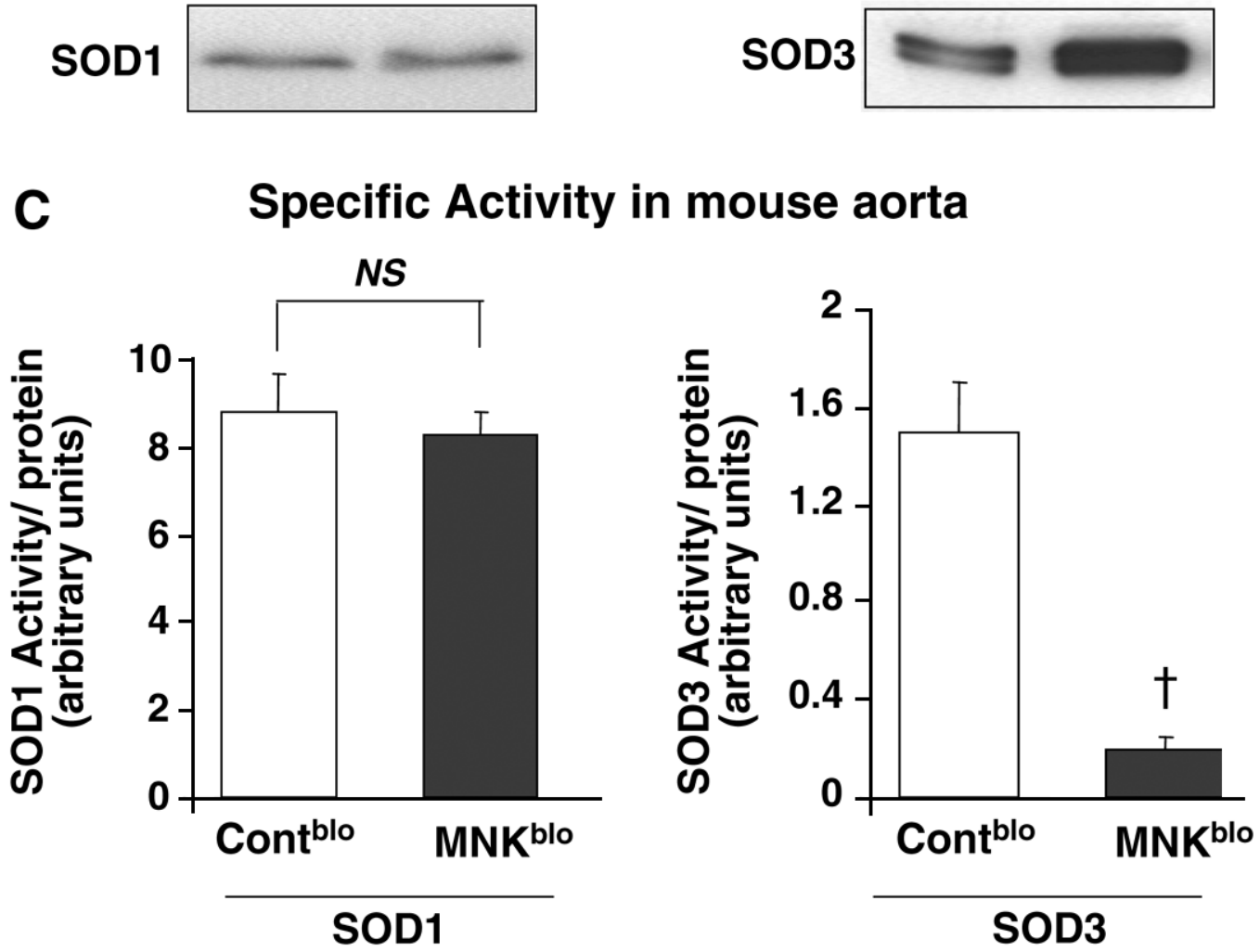

Figure 6. Activity $(\boldsymbol{A})$, protein expression $(\boldsymbol{B})$, and specific activity $(\boldsymbol{C})$ of SOD3 and SOD1 in aortas from control littermates (Cont $\left.{ }^{\text {blo }}\right)$ and blotchy MNK mutant $\left(\mathrm{MNK}^{\text {blo }}\right)$ mice $(19,20,25)$. Aortas were homogenized as previously described (28). The activity, protein expression, and specific activity of SOD1 and SOD3 were determined as described in Fig. 1. Aortas from four mice were combined for each experiment ( $n=3$ for each data point). The results are presented as mean \pm SE, and the values are expressed as units per milligram of total protein. ${ }^{\dagger} P<0.01$ vs. control. ${ }^{*} P<0.05$ vs. control. 
Fig. 7

\section{A Lucigenin Chemiluminescence}
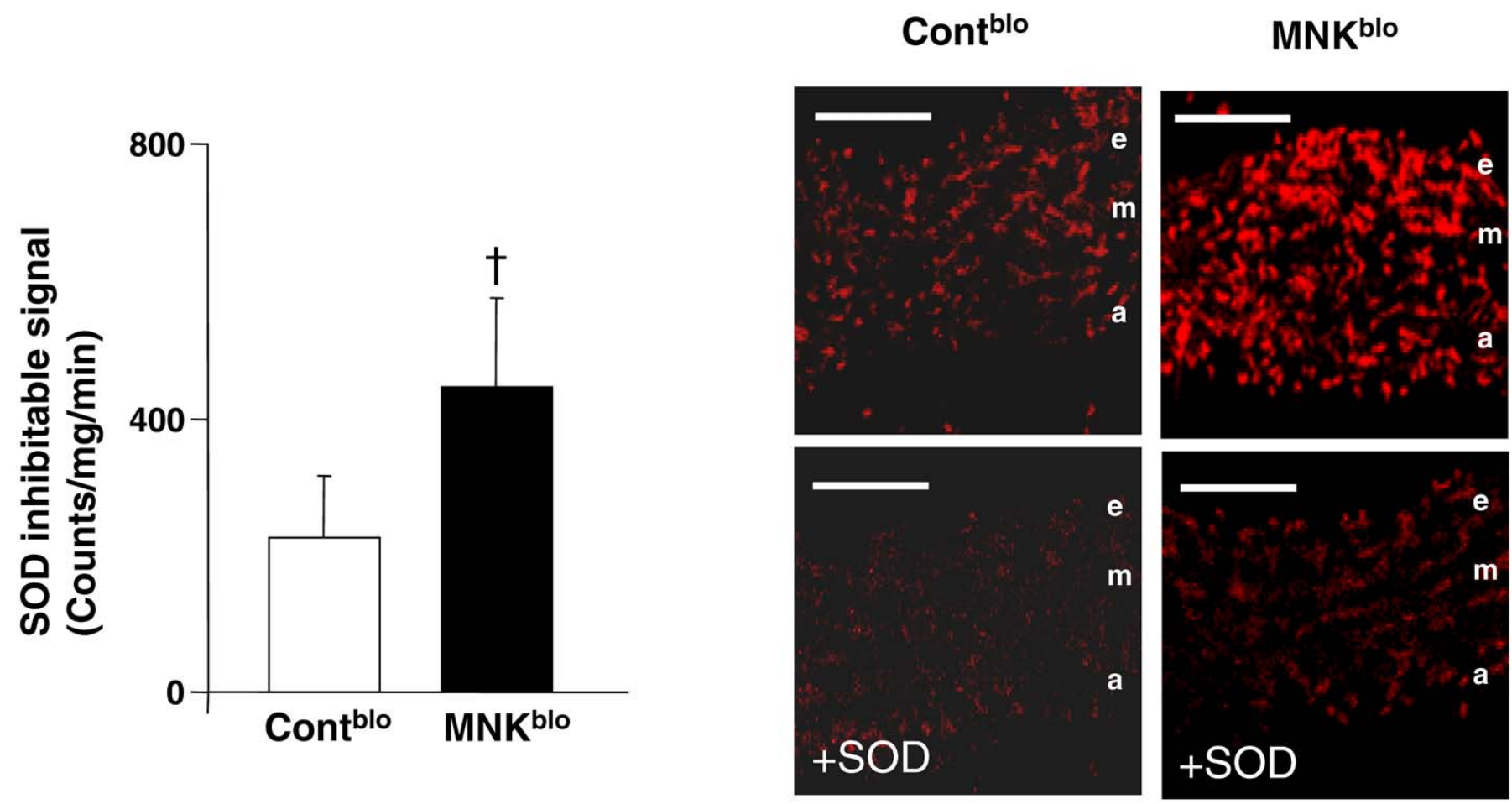

$25 \mu \mathrm{m}$

Figure 7. A) Vascular $\mathrm{O}_{2}{ }^{--}$production in aortas from control littermates $\left(\right.$Cont $\left.{ }^{\text {blo }}\right)$ and blotchy MNK mutant $\left(\mathrm{MNK}^{\text {blo }}\right)$ mice as determined with lucigenin-enhanced chemiluminescence $(5 \mu \mathrm{mol} / 1 ; n=5)$. Fresh control and MNK mutant mouse aortas were incubated with or without PEG-SOD $(500 \mathrm{U} / \mathrm{ml})$ for $30 \mathrm{~min}$ before assay. ${ }^{\dagger} P<0.01 \mathrm{vs}$. control mice. B) In situ detection of superoxide production with dihydroethidium (DHE) in aortas from Cont ${ }^{\text {blo }}$ and $\mathrm{MNK}^{\text {blo }}$ mutant mice. Freshfrozen control and MNK mutant mouse aortas were incubated with DHE for $30 \mathrm{~min}$ (top panels). SOD (500 U/ml) applied topically to the sequential cut sections of control and MNK mutant mouse aortas during the 30-min incubation with DHE (bottom panels). SOD abolished the fluorescence, confirming specificity of the fluorescent signal for $\mathrm{O}_{2}^{-}$. Data are representative of 3 separate experiments. e, endothelium; m, media; a, adventitia. 
Fig. 8

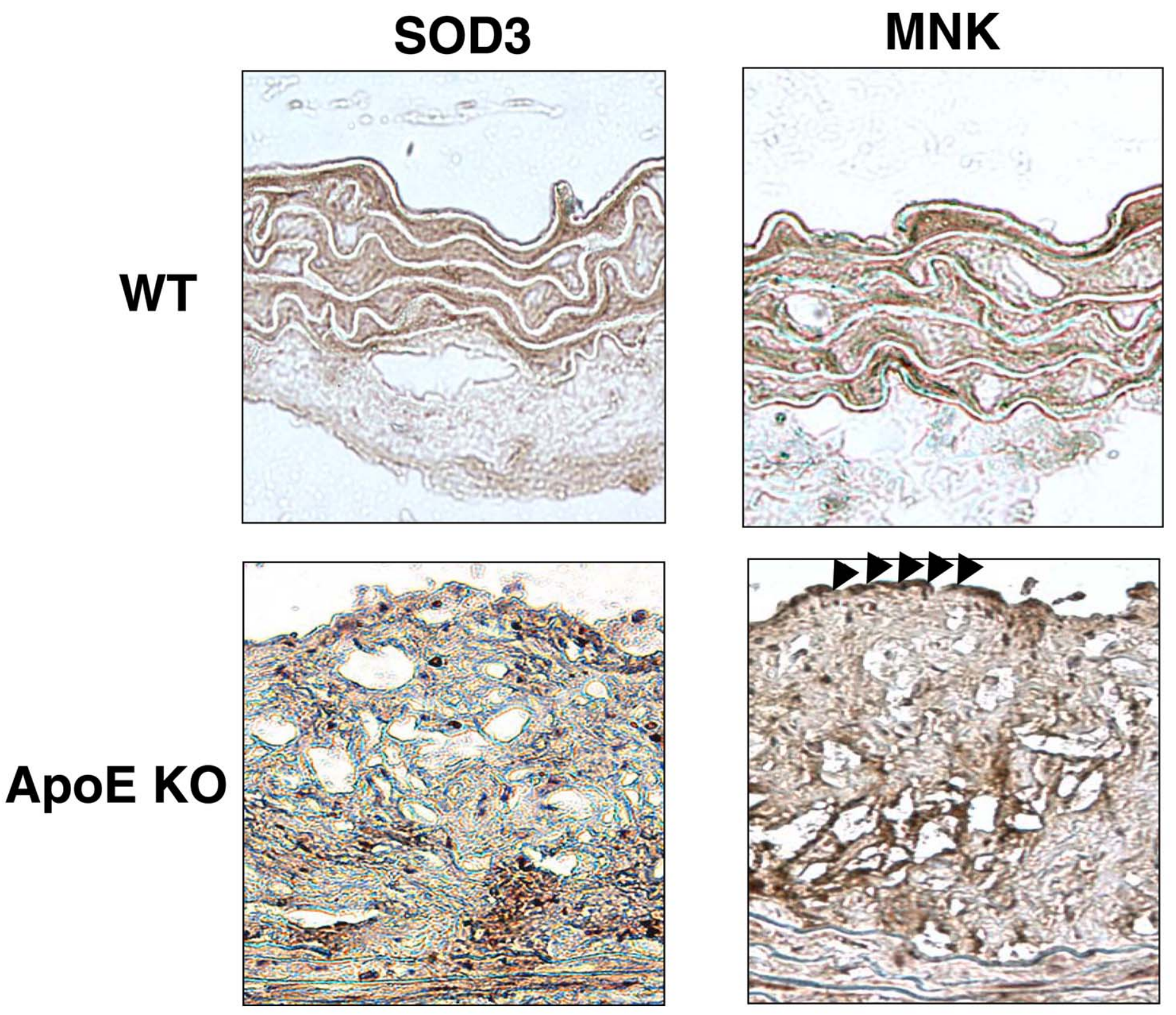

Figure 8. Immunohistochemical detection of SOD3 and $\mathrm{MNK}$ in control and $\mathrm{ApoE}^{-/-}$mouse aortas. Immunostaining was performed using an anti-SOD3 or MNK antibody followed by a biotin-conjugated goat anti-rabbit IgG. Immunoreactivity for SOD3 and MNK were prominent in the intimal lesion in $\mathrm{ApoE}^{-/-}$mice (lower panels, brown staining). Black arrows indicate intense staining for MNK in endothelium of atherosclerotic vessels. Images are representative of 3 separate experiments. Absence of staining when the primary antibody was omitted. 